Research Paper

\title{
Thyroid cancer 1 (C8orf4) shows high expression, no mutation and reduced methylation level in lung cancers, and its expression correlates with $\beta$-catenin and DNMT1 expression and poor prognosis
}

\author{
Yi-Wen Zheng ${ }^{1, *}$, Li Zhang ${ }^{1, *}$, Yuan Wang ${ }^{1}$, Song-Yan Chen ${ }^{1}$, Lei Lei ${ }^{1}$, Na Tang ${ }^{1}$, \\ Da-Lei Yang ${ }^{1}$, Lin-Lin Bai ${ }^{1}$, Xiu-Peng Zhang ${ }^{1}$, Gui-Yang Jiang ${ }^{1}$, Lian-He Yang ${ }^{1}$, \\ Hong-Tao X ${ }^{1}{ }^{\text {, }}$ Qing-Chang Li $^{1}$, Xue-Shan Qiu ${ }^{1}$ and En-Hua Wang ${ }^{1}$ \\ ${ }^{1}$ Department of Pathology, The First Affiliated Hospital and College of Basic Medical Sciences of China Medical University, \\ Shenyang 110001, China \\ *These authors have contributed equally to this work
}

Correspondence to: Hong-Tao Xu, email: Xuht@cmu.edu.cn

Keywords: C8orf4, mutation, methylation, $\beta$-catenin, DNMT1

Received: February 02, $2017 \quad$ Accepted: March 21, $2017 \quad$ Published: April 06, 2017

Copyright: Zheng et al. This is an open-access article distributed under the terms of the Creative Commons Attribution License 3.0 (CC BY 3.0), which permits unrestricted use, distribution, and reproduction in any medium, provided the original author and source are credited.

\section{ABSTRACT}

Thyroid cancer 1 (TC1, C8orf4) plays important roles in tumors. The aim of this study was to examine the protein expression levels, methylation status, and mutational status of TC1 (C8orf4) in lung cancers, and investigate the correlation between TC1, other members of the Wnt signaling pathway, and lung cancer. TC1 expression levels were assessed via immunohistochemical staining in 179 cases of lung cancer. $\beta$-catenin, TCF4, Axin, Disabled-2, Chibby, and DNA methyltransferase-1 (DNMT1) expressions were also examined. Bisulfite sequencing PCR analysis was used to examine the methylation status of the C8orf4 locus, while PCR analysis and direct sequencing were used to determine its mutational status. We found high TC1 expression correlated with poor differentiation, advanced TNM stage, lymphatic metastasis, and poor prognosis in lung cancer patients. TC1 expression also correlated with $\beta$-catenin and DNMT1 expressions. No mutations in C8orf4 were detected. However, methylation levels of C8orf4 in lung cancers were lower than in corresponding normal lung tissues. In conclusion, high TC1 expression is implicated in lung cancer progression and correlates with poor prognosis in lung cancer. Reduced methylation levels might be responsible for the elevated TC1 expression levels. TC1, $\beta$-catenin, and DNMT1 can synergistically activate $\mathbf{W n t} / \beta$-catenin signaling in lung cancers.

\section{INTRODUCTION}

Thyroid cancer 1 (TC1, C8ofr4) was originally identified in papillary thyroid cancer and its surrounding normal thyroid tissue less than two decades ago $[1,2]$. It has multiple functions and is believed to play important roles in cell cycle control as well as transcriptional and translational regulation [1-5]. Several studies reported that $\mathrm{TC} 1$ functions as a regulator of the $\mathrm{Wnt} / \beta$-catenin signaling pathway through its interactions with Chibby [4]. Chibby is a conserved nuclear protein that binds $\beta$-catenin and antagonizes $\beta$-catenin-mediated transcription [6-8]. TC-1 interacts with Chibby via its transient helical structure, and thereby enhances the $\mathrm{Wnt} / \beta$-catenin signaling pathway by releasing $\beta$-catenin from Chibby. Free nuclear $\beta$-catenin then forms a complex with transcription factors of the T-cell factor/lymphoid enhancer factor (TCF/LEF) family, leading to the activation of Wnt target genes [9]. Thus, $\mathrm{TC} 1$ is considered a positive regulator of the Wnt signaling pathway $[4,10,11]$. Besides regulating the $\mathrm{Wnt} / \beta$-catenin signaling pathway, TC1 is also a NF-kB-target gene 
and can be up-regulated by transforming growth factor $\beta$ pathway and the IL- $1 \beta / \mathrm{TNF}-\alpha$ and fibroblast growth factor receptor 2 pathways $[3,5,12,13]$. Heat shock and various cellular stresses can induce the expression of TC1, and TC1 serves as a novel heat shock response regulator [14]. TC1 is involved in the mitogen-activated ERK1/2 signaling pathway and promotes the G1- to S-phase transition of the cell cycle [15]. Recently, TC1 was also reported as a novel hematopoietic regulator in mice [16].

Although originally identified in papillary thyroid cancer, TC1 is ubiquitously expressed in human tissues [2]. Studies have shown that TC1 expression levels positively correlates with development of many malignancies including thyroid cancer [1, 17], gastric cancer [10], breast cancer [13], ovarian carcinomas [18], oral tongue squamous cell carcinomas [19], and hematological malignancies [20, 21]. Expression levels of TC1 correlate with poor clinical outcome and decreased survival in patients with gastric cancer and hematological malignancies [10, 20]. However, reduced expression of $\mathrm{TC} 1$ has been reported in colon cancer tissue relative to normal mucosa [3]. A recent report by $\mathrm{Zhu}$ et al. demonstrated that TC1 negatively regulated self-renewal of liver cancer stem cells via suppression of Notch2 signaling, thereby implicating a negative role for TC1 in tumor development [22]. Thus, understanding the precise functions and regulatory mechanisms of TC1 in cancers warrants further investigation.

Very little information exists regarding the role of TC1 in lung cancers $[23,24]$. The regulatory mechanisms of TC1 expression, and its implications on clinicopathological factors and on outcomes of lung cancer patients remain unclear. In this study, we examined the protein expression levels, gene methylation status, and mutational status of TC1 in lung cancer samples and explored the mechanisms underlying TC1 overexpression. We also investigated the correlation between expression levels of TC1 and other members of the Wnt/ $\beta$-catenin signaling pathway, and analyzed the implications of TCI levels on clinicopathological factors and prognosis of lung cancer patients.

\section{RESULTS}

\section{High TC1 expression correlates with poor differentiation, advanced TNM stage, lymphatic metastasis and poor prognosis in lung cancers}

High TC1 expression was detected in 116 of 179 lung cancer cases. TC1 expression was primarily cytoplasmic with positive nuclear expression detected in 17 cases (Figure 1). As shown in Table 1, the high TC1 expression correlated with poor differentiation $(P=0.008)$, advanced TNM stage $(P=0.003)$ and lymphatic metastasis $(P=0.003)$ of lung cancers. TC1 expression did not correlate with the patients' sex $(P=0.257)$, age $(P=0.776)$ or histological type of lung cancers $(P=0.210)$.

A follow-up analysis was performed with 95 lung cancer patients. Kaplan-Meier curve and log rank analysis demonstrated that the average survival time of patients with high TC1 expression $(36.220 \pm$ 3.192) was shorter than that of patients with low TC1
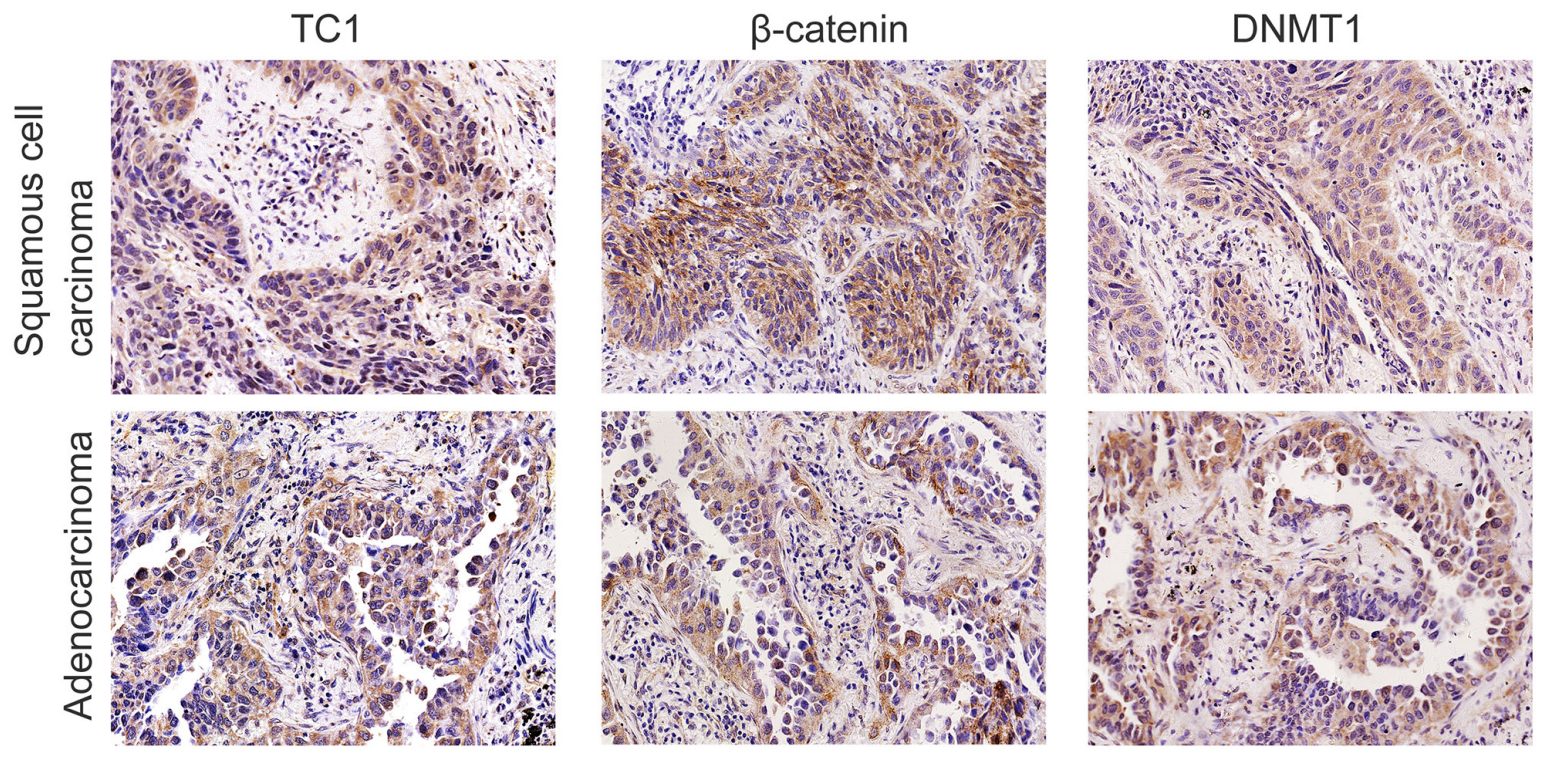

Figure 1: Expressions of TC1, $\beta$-catenin, and DNMT1 in representative lung cancer cases. In a lung squamous cell carcinoma case, TC1 was highly expressed in the cytoplasm. Some cancer cells also showed nuclear staining of TC1. Expression of $\beta$-catenin and DNMT1 were both positive in the same case. In another adenocarcinoma case, TC1 was highly expressed in the cytoplasm. Some cancer cells also showed nuclear staining of TC1. Expression of $\beta$-catenin and DNMT1 were both positive in the same case (Original magnification, 200×; streptavidin-peroxidase immunohistochemistry method). 
Table 1: The correlation between the expression of TC1 and clinicopathologycal factors of lung cancers

\begin{tabular}{|c|c|c|c|c|c|c|c|}
\hline & \multirow[b]{2}{*}{$\mathbf{n}$} & \multicolumn{3}{|c|}{ TC1 cytoplasmic expression } & \multicolumn{3}{|c|}{ TC1 nuclear expression } \\
\hline & & Low & High & $P$ value & Negative & Positive & $P$ value \\
\hline Sex & & & & 0.257 & & & 0.707 \\
\hline Male & 92 & 36 & 56 & & 84 & 8 & \\
\hline Female & 87 & 27 & 60 & & 78 & 9 & \\
\hline Age & & & & 0.776 & & & 0.723 \\
\hline$<60$ & 102 & 35 & 67 & & 93 & 9 & \\
\hline$\geq 60$ & 77 & 28 & 49 & & 69 & 8 & \\
\hline Histological type & & & & 0.210 & & & 0.600 \\
\hline Squamous cell carcinoma & 63 & 26 & 37 & & 58 & 5 & \\
\hline Adenocarcinoma & 116 & 37 & 79 & & 104 & 12 & \\
\hline Differentiation & & & & 0.008 & & & 0.745 \\
\hline Well & 52 & 27 & 25 & & 46 & 6 & \\
\hline Moderate & 100 & 30 & 70 & & 92 & 8 & \\
\hline Poor & 27 & 6 & 21 & & 24 & 3 & \\
\hline TNM stage & & & & 0.003 & & & 0.082 \\
\hline I & 87 & 41 & 46 & & 83 & 4 & \\
\hline II & 72 & 19 & 53 & & 62 & 10 & \\
\hline III & 20 & 3 & 17 & & 17 & 3 & \\
\hline Lymphatic metastasis & & & & 0.003 & & & 0.183 \\
\hline No & 101 & 45 & 56 & & 94 & 7 & \\
\hline Yes & 78 & 18 & 60 & & 68 & 10 & \\
\hline
\end{tabular}

expression $(52.800 \pm 2.210)(P<0.001)$ (Figure 2$)$. Poor differentiation $(P<0.001)$, advanced TNM stage $(P<0.001)$, and lymphatic metastasis $(P<0.001)$ also correlated with a lower survival rate (Figure 2). Further, multivariate Cox regression analysis (method: Forward Stepwise) revealed that high expression levels of TC1 $(P=0.001$; hazard ratio: $3.376 ; 95 \% \mathrm{CI}: 1.632-6.985)$ and lymphatic metastasis $(P=0.009$; hazard ratio: $2.416 ; 95 \%$ CI: 1.252-4.661) were independent prognostic factors for lung cancer patients.

\section{Expression of TC1 correlates with the expressions of $\beta$-catenin, DNMT1, and Chibby}

As shown in Table 2, along with the examination of TC1, expression levels of DNMT1, $\beta$-catenin, TCF4, Axin, Dab2, and Chibby were also examined in 84 lung cancer specimens. High cytoplasmic expression of TC1 positively correlated with expression levels of DNMT1 $(P<0.001$; correlation coefficient $=0.502)$ and $\beta$-catenin $(P=0.003$; correlation coefficient $=$ 0.324 ) (Figure 1). Furthermore, $\beta$-catenin expression levels also correlated with the expression of DNMT1 $(P=0.020$; correlation coefficient $=0.254)$. Thus, the expressions levels of TC1, $\beta$-catenin and DNMT1 correlated with each other. In addition, high cytoplasmic expression of TC1 negatively correlated with nuclear expression of Chibby $(P=0.001$; correlation coefficient $=-0.353)$. Nuclear expression of TC1 correlated with nuclear expressions of Axin $(P=0.004$; correlation coefficient $=0.313)$ and Dab2 $(P<0.001$; correlation coefficient $=0.399)$. Detailed correlative data of the examined proteins are listed in the Supplementary Table 1.

\section{C8orf 4 is not mutated in lung tumors or normal lung tissues}

Sequence analysis of the C8orf4 gene locus was performed on 70 lung cancer specimens as well as 30 normal lung tissues. Following PCR amplification and direct sequencing, no mutations in the C8orf4 gene were detected in either lung cancer tissues or normal lung tissues (Figures 3A and 4). 


\section{Methylation levels of C8orf4 in lung cancer specimens are lower than that in corresponding normal lung tissues}

We analyzed the gene sequence of C8orf4 from $-2000 \mathrm{bp}$ to $1000 \mathrm{bp}$ using the online $\mathrm{CpG}$ island predict program from The Li Lab (http://www.urogene.org/ methprimer/index.html). The $\mathrm{CpG}$ island of the C8orf4 gene was located closer to the $5^{\prime}$ end of the exon, near the start codon. After bisulfite sequencing PCR (BSP), the methylation status of each $\mathrm{CpG}$ site was examined in 30 pairs of lung cancer tissues and their corresponding normal lung tissues (Figure 3B). As indicated in Table 3 and Figure 5, complete methylation was observed at the CpG sites at $41 \mathrm{bp}$ and $49 \mathrm{bp}$ from the start codon, in 17 and 21 cases of lung cancer, respectively, which was less than that in corresponding normal lung tissues ( 28 cases for the $41 \mathrm{bp}$ site $[P=0.001]$ and 30 for the $49 \mathrm{bp}$ site $[P=0.003])$. Complete methylation of $\mathrm{CpG}$ sites at $94 \mathrm{bp}$ and $105 \mathrm{bp}$ was observed in all lung cancer samples and their corresponding normal lung tissues.
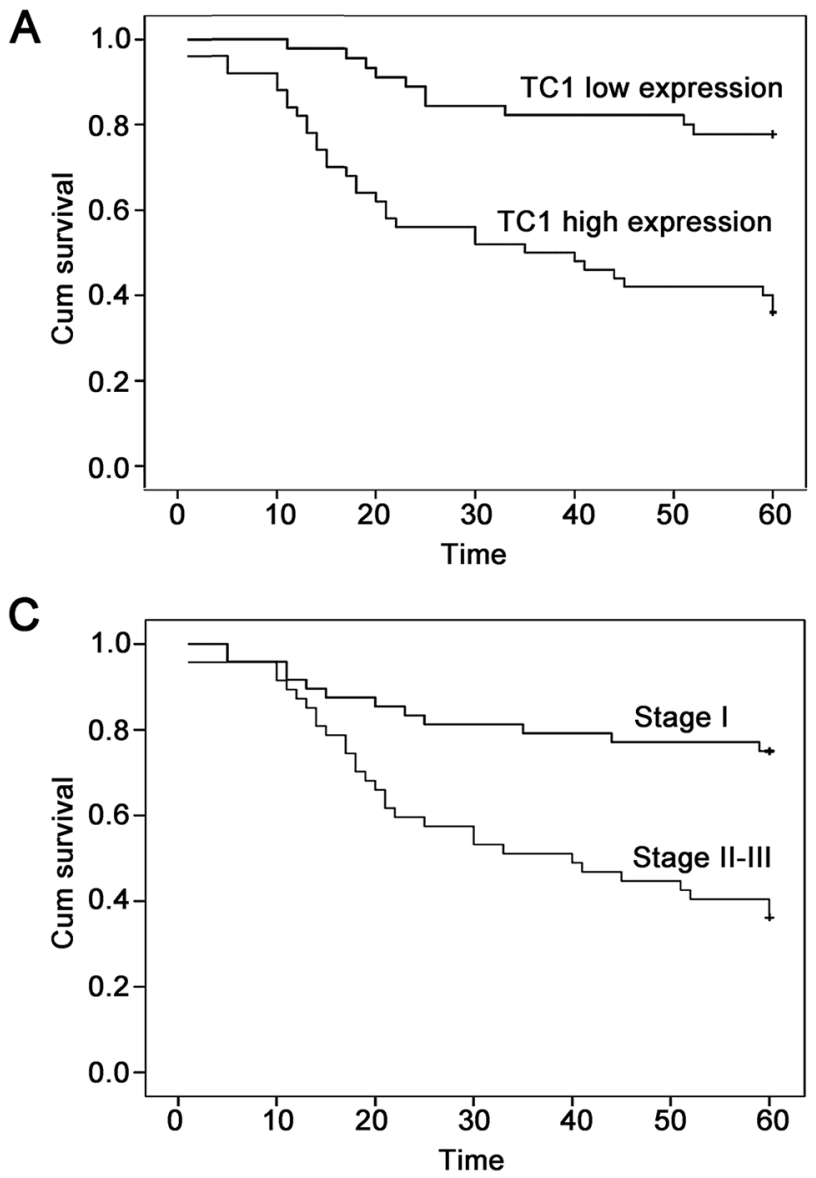

Although the levels of complete methylation at $\mathrm{CpG}$ sites of $13 \mathrm{bp}(P=0.102), 44 \mathrm{bp}(P=0.157)$, and $81 \mathrm{bp}(P=$ $0.157)$ were lower in lung cancer tissues than that in their corresponding normal lung tissues, these differences were not statistically significant. Furthermore, the methylation status of the $49 \mathrm{bp} \mathrm{CpG}$ site correlated with those of the 41 bp $(P<0.001$; correlation coefficient $=0.749)$ and $44 \mathrm{bp}$ $(P=0.408$; correlation coefficient $=0.025) \mathrm{CpG}$ sites, and the methylation status of the $44 \mathrm{bp} \mathrm{CpG}$ site correlated with the $81 \mathrm{bp} \mathrm{CpG}$ site $(P=0.010$; correlation coefficient $=0.464)$. Correlation between the methylation status and clinicopathological factors in lung cancer specimens was also investigated, but no statistically significant results were observed (data not shown).

\section{DISCUSSION}

Several studies reported high expression levels of TC1 across a wide range of tumors, and a positive association with malignancy $[10,13,17-19,23,24]$. However, reduced expression of TC1 was observed in
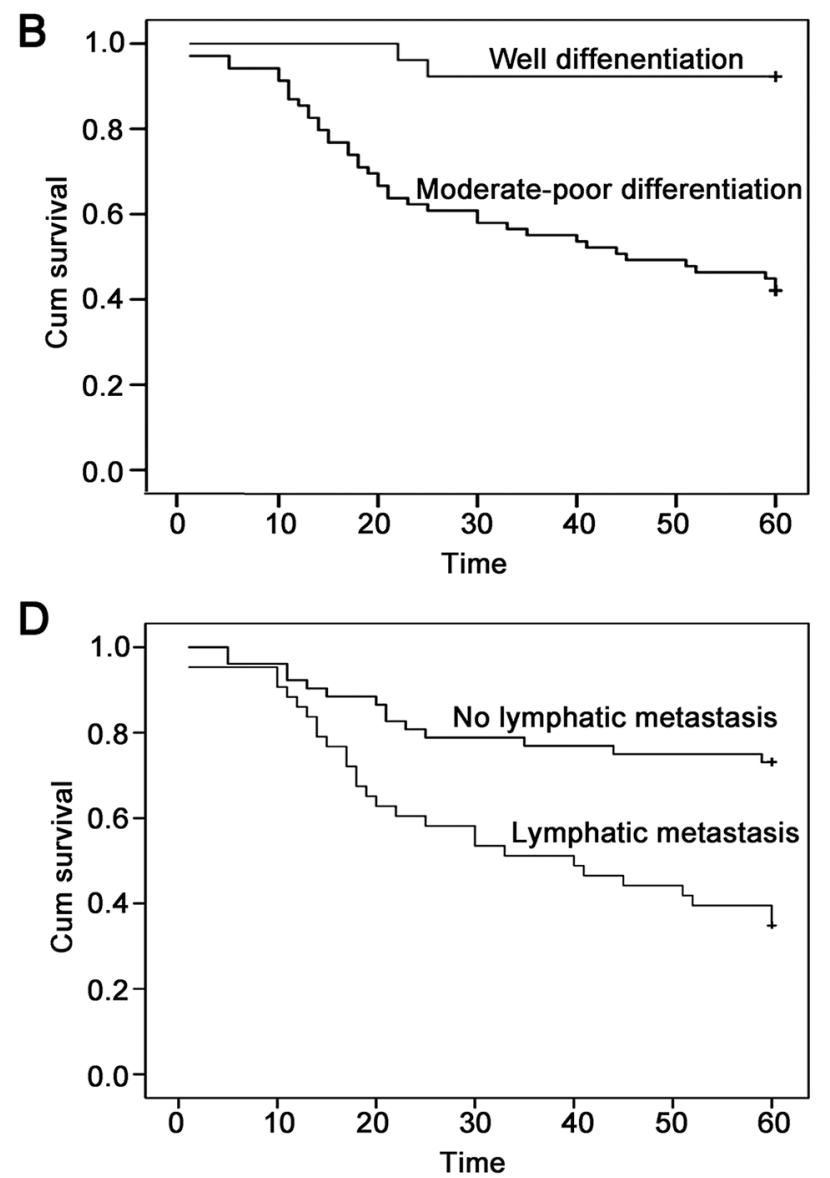

Figure 2: The Kaplan-Meier curves of lung cancer patients. (A) The Kaplan-Meier curve of lung cancer patients with high or low TC1 expression. (B) The Kaplan-Meier curve of lung cancer patients with well or moderate-poor differentiation. (C) The KaplanMeier curve of lung cancer patients with TNM stage I or stage II-III. (D) The Kaplan-Meier curve of lung cancer patients with or without lymphatic metastasis. 
Table 2: The correlations between the expression of TC1 and DNMT1 or members of Wnt signaling pathway in lung cancers

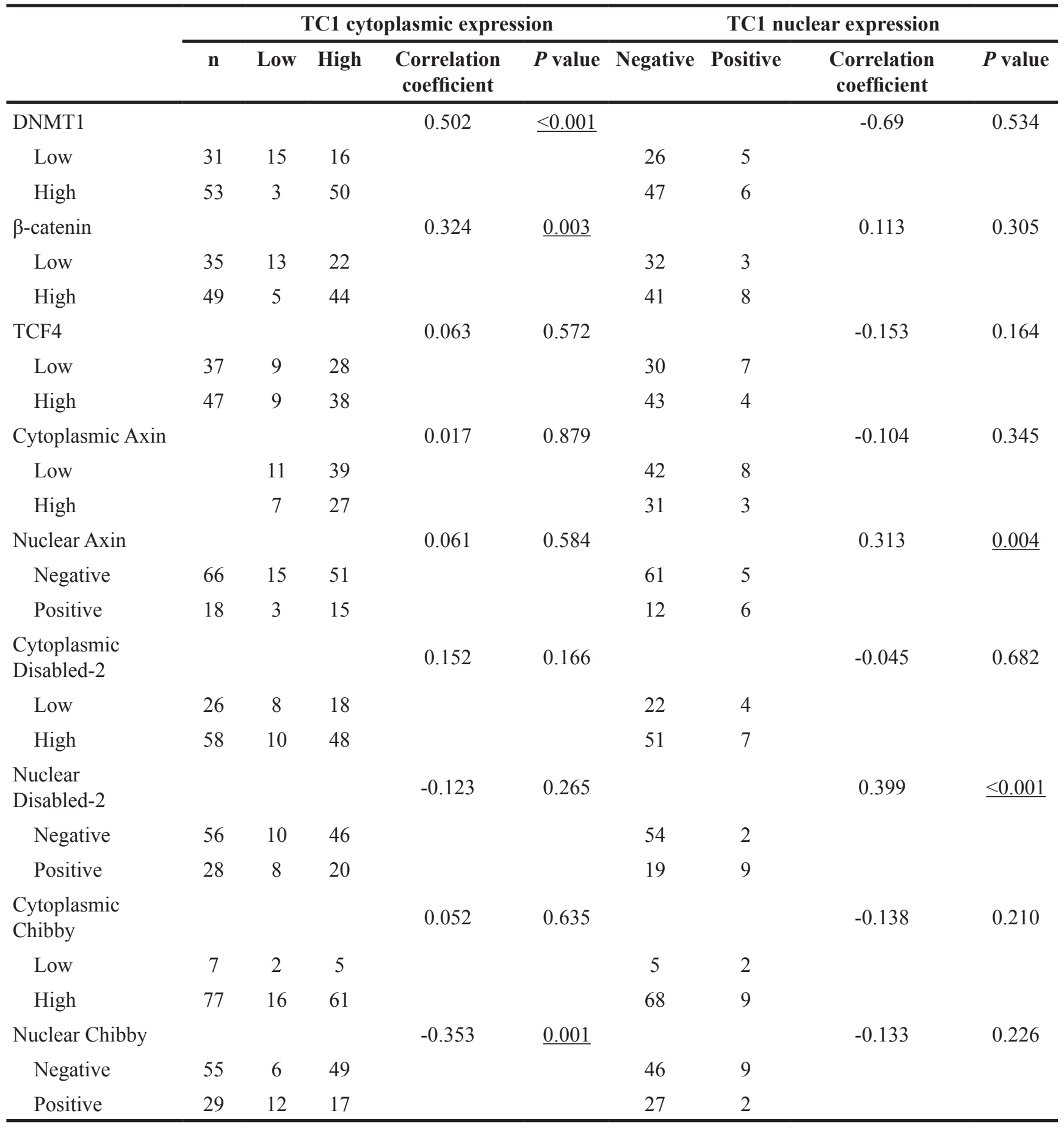

Underline: statistical significant.

colon cancer tumors relative to normal mucosa [3]. TC1 likely exhibits pro- or anti-tumorigenic roles in a tumor type-specific manner. Consistent with previous reports, our study demonstrated high expression levels of TC1 correlates with the tumor development and decreased survival, and is a predictor of poor prognosis in lung cancer patients.
Because the mechanism underlying abnormal TC1 expression in tumors had remained unclear, we hypothesized that gene methylation or mutations in TC1 contribute to the high expression level in lung cancer. To our knowledge, this is the first study examining the methylation status as well as mutational status of the C8orf4 gene in tumors. No mutation in the C8orf4 
A

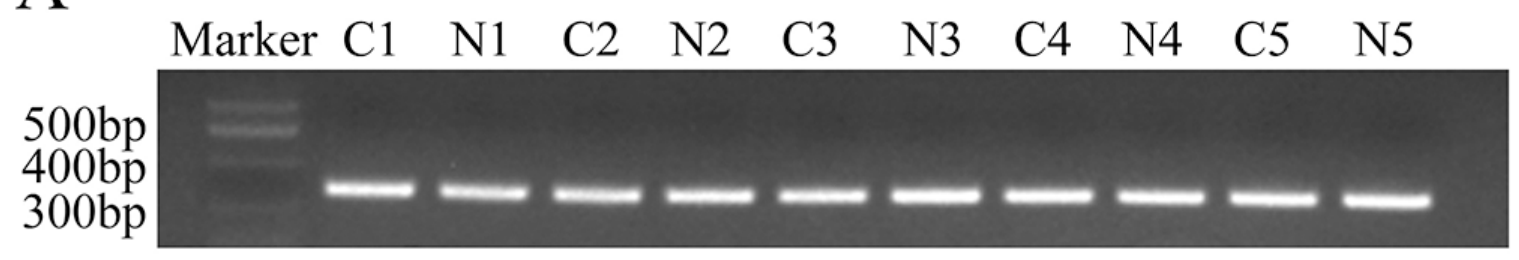

B

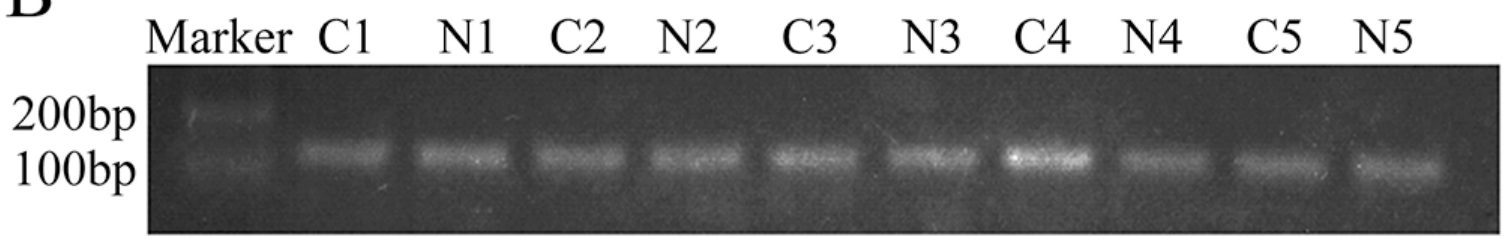

Figure 3: PCR analysis of the C8orf4 gene locus and the CpG island of C8orf4 after bisulfite conversion. (A) The C8orf4 gene was amplified and the product length was $315 \mathrm{bp}$. (B) After bisulfite conversion, the $\mathrm{CpG}$ island of C8orf4 was amplified and the product length was $144 \mathrm{bp}$. C: lung cancer tissues. N: corresponding normal lung tissues.

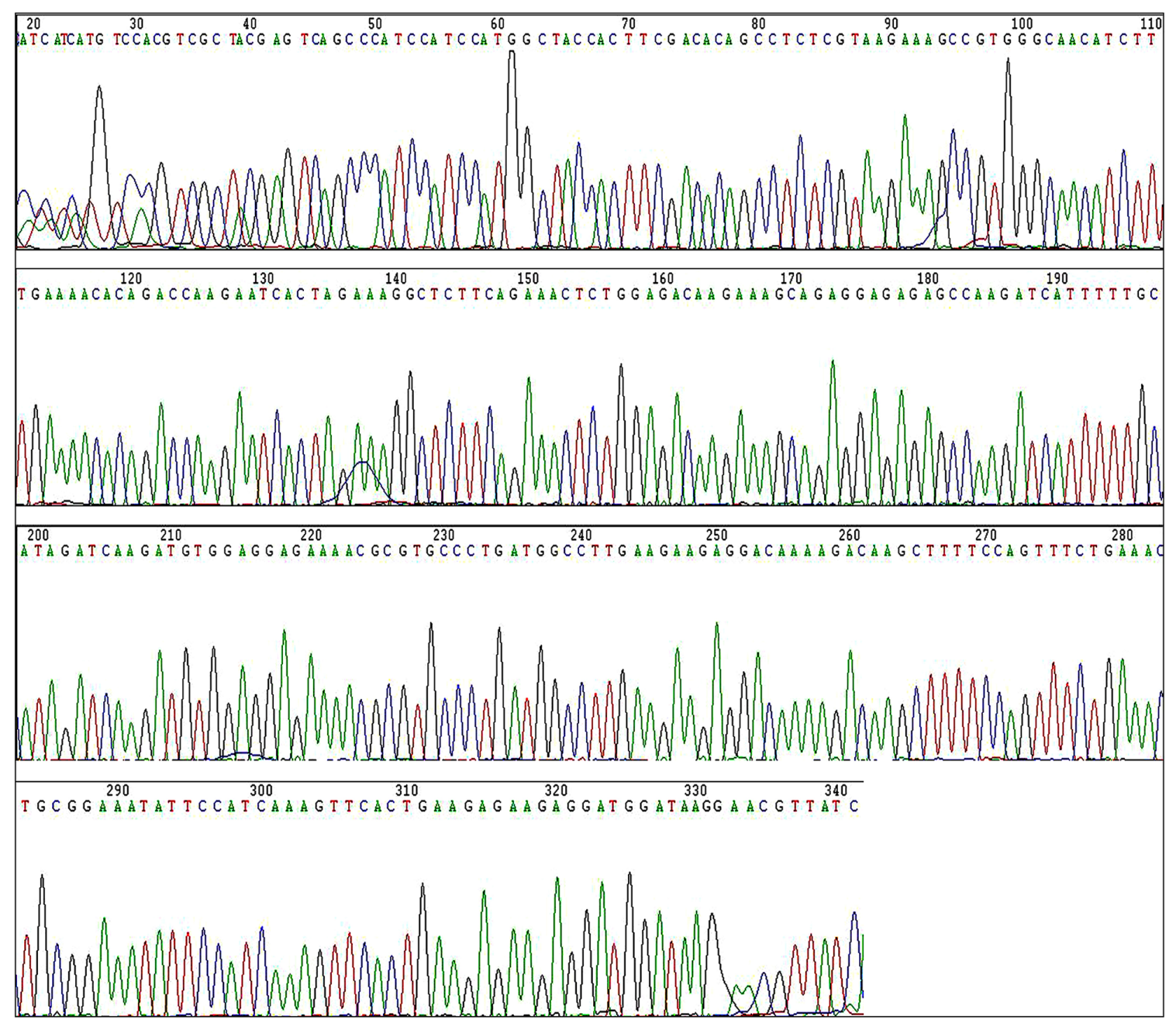

Figure 4: The result of sequencing of the C8orf4 gene in a representative lung cancer case. Sequencing of the $C 80 r f 4$ gene did not find any mutation in lung cancer tissues. 
Table 3: The methylation status of TC1 in lung cancers and corresponding normal lung tissues

\begin{tabular}{|c|c|c|c|c|}
\hline \multirow[b]{2}{*}{ The CpG site } & \multicolumn{4}{|c|}{ The methylation status of TC1 } \\
\hline & Methylation & Unmethylation & $\begin{array}{l}\text { Wilcoxon signed } \\
\text { ranks test }\end{array}$ & $P$ value \\
\hline $13 \mathrm{bp}$ & & & 1.633 & 0.102 \\
\hline Lung cancer & 4 & 26 & & \\
\hline NL & 8 & 22 & & \\
\hline $41 \mathrm{bp}$ & & & 3.317 & $\underline{0.001}$ \\
\hline Lung cancer & 17 & 13 & & \\
\hline NL & 28 & 2 & & \\
\hline $44 \mathrm{bp}$ & & & 1.414 & 0.157 \\
\hline Lung cancer & 28 & 2 & & \\
\hline NL & 30 & 0 & & \\
\hline $49 \mathrm{bp}$ & & & 3.000 & $\underline{0.003}$ \\
\hline Lung cancer & 21 & 9 & & \\
\hline NL & 30 & 0 & & \\
\hline \multicolumn{5}{|l|}{$81 \mathrm{bp}$} \\
\hline Lung cancer & 28 & 2 & 1.414 & 0.157 \\
\hline NL & 30 & 0 & & \\
\hline $94 \mathrm{bp}$ & & & 0.000 & 1.000 \\
\hline Lung cancer & 30 & 0 & & \\
\hline NL & 30 & 0 & & \\
\hline $105 \mathrm{bp}$ & & & 0.000 & 1.000 \\
\hline Lung cancer & 30 & 0 & & \\
\hline NL & 30 & 0 & & \\
\hline
\end{tabular}

NL: corresponding normal lung tissue.

Underline: statistical significant.

locus was detected in either lung tumor specimens or the corresponding normal lung tissues, suggesting a mechanism other than mutation in TC1 contributes to high expression levels in lung cancer. BSP analysis revealed that the degree of methylation at the $41 \mathrm{bp}$ and $49 \mathrm{bp} \mathrm{CpG}$ sites in lung cancer tissues was lower than that in corresponding normal lung tissues. These results suggest that reduced methylation levels contribute to high expression of $\mathrm{TC} 1$ in lung cancers, and that the $41 \mathrm{bp}$ and $49 \mathrm{bp} \mathrm{CpG}$ sites serve as key methylation sites that likely modulate the expression levels of TC1.

It is believed that $\mathrm{TC} 1$ promotes tumor development primarily by enhancing the activity of the $\mathrm{Wnt} / \beta$-catenin signaling pathway $[10,13,19,23]$. However, the relationship between TC1 and other key members of the $W n t / \beta$-catenin signaling pathway is unclear. We thus examined the correlation between TC1 and other Wnt pathway members including $\beta$-catenin, Chibby, TCF4, Axin, and Dab2 in lung cancers. The expression of TC1 positively correlates with the expression of $\beta$-catenin, and negatively correlates with the nuclear expression of Chibby. These data provided further evidence that TC1 inhibits the function of nuclear Chibby while enhancing the activity of $\beta$-catenin. We also observed that nuclear expression of TC1 correlated with nuclear expression of Axin and Dab2, which are both important inhibitors 
of the Wnt/ $\beta$-catenin signaling pathway [25-27]. Since the number of cases containing TC1 nuclear expression was very small, these results need further confirmation. Recent report revealed that DNMT1 expression correlates with $\beta$-catenin expression, colocalizes with $\beta$-catenin, and regulates the activity of the $\mathrm{Wnt} / \beta$-catenin signaling pathway $[8,28]$. The present study observed that the expression of TC1, $\beta$-catenin, and DNMT1 were correlated with each other, indicating that these three proteins might promote the activity of the Wnt signaling pathway in a synergistic manner. Recent studies revealed that TC1 plays a role in the regulation of stem cells, such as hematopoietic stem cells [16], adipocyte-derived stem cells [29], and liver cancer stem cells [22] via the Wnt/ $\beta$ catenin signaling pathway or Notch signaling pathway. Therefore, TC1 may participate in tumorigenesis and the transformation of cancer stem cells, which require further studies.

In summary, high TC1 expression is implicated in lung cancer progression and correlates with poor prognosis in lung cancer patients. Our data indicated that reduced methylation levels, rather than gene mutation, might be the underlying cause for high TC1 expression in lung cancer. Finally, our results further suggested that $\mathrm{TC} 1, \beta$-catenin and DNMT1 might promote the Wnt signaling activity in a synergistic manner.

A

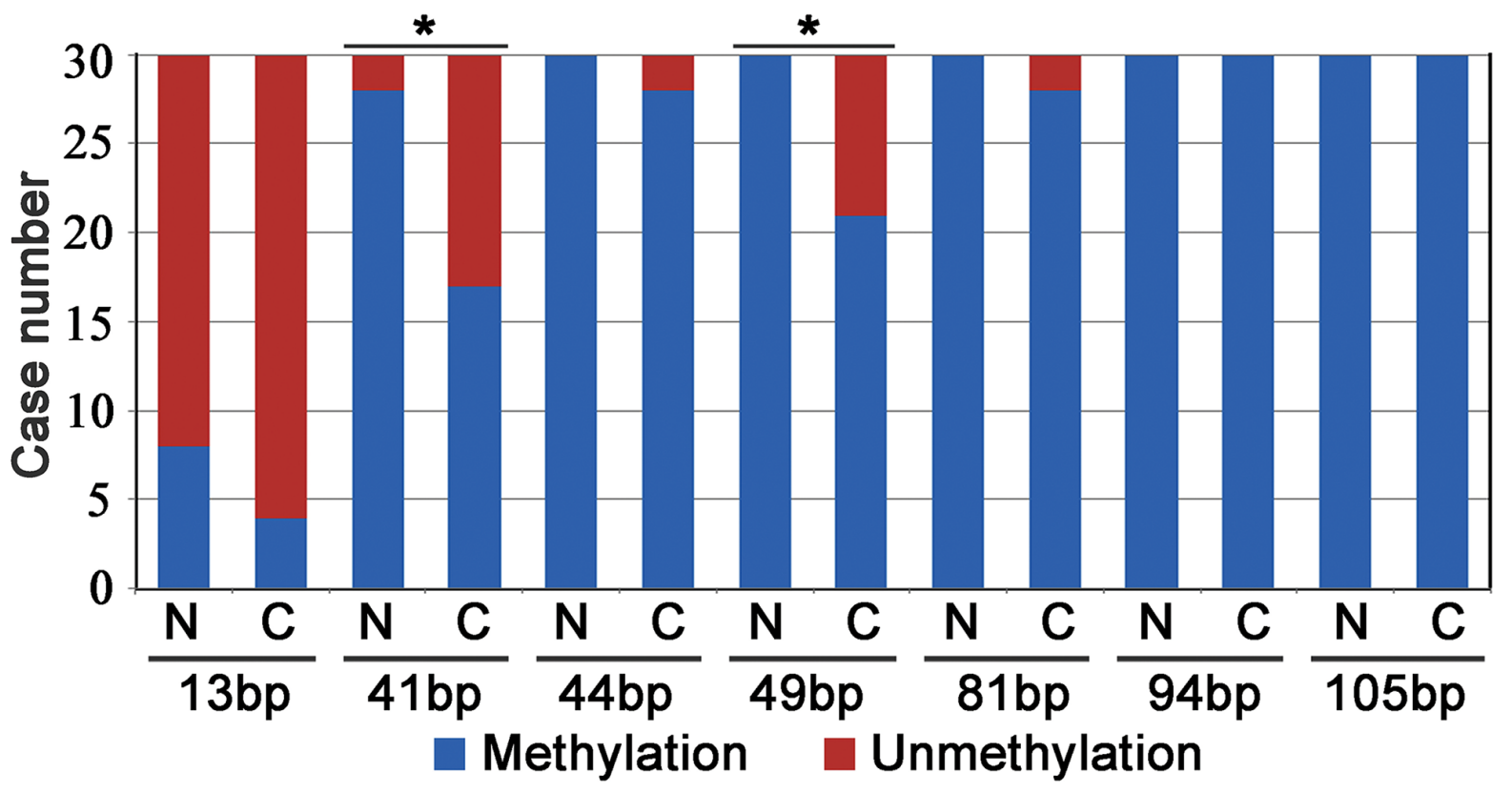

B

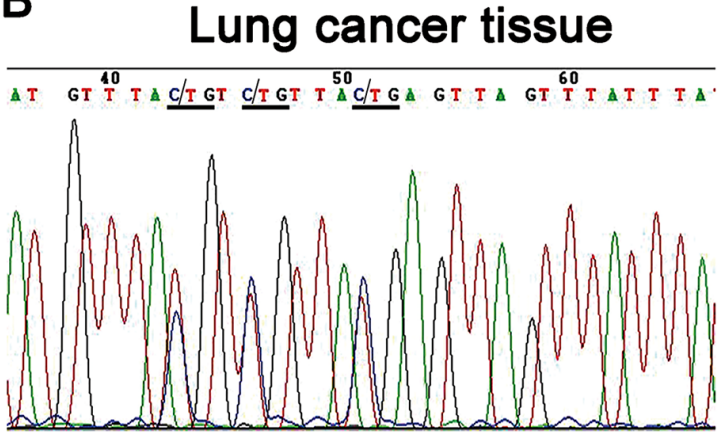

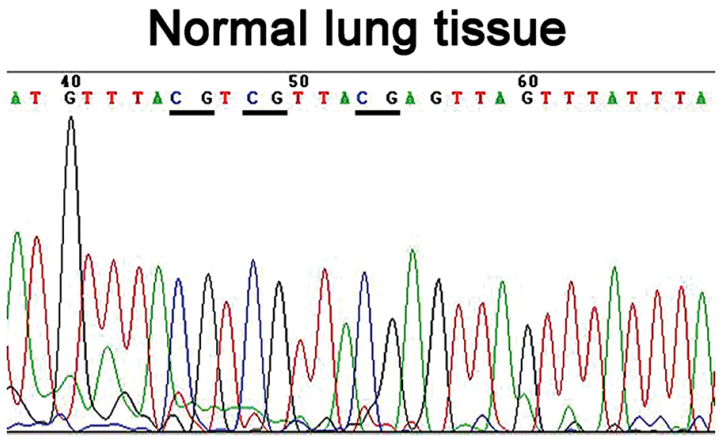

Figure 5: The results of Bisulfite sequencing PCR (BSP) analysis. (A) The number of cases with methylation or unmethylation at the $\mathrm{CpG}$ sites in lung cancer tissues and their corresponding normal lung tissues. N: normal lung tissue; C: lung cancer tissue; $*: P<0.05$. (B) In a representative lung cancer case, the $\mathrm{CpG}$ sites (underlined) at the $41 \mathrm{bp}, 44 \mathrm{bp}$, and $49 \mathrm{bp}$ were semi-methylated, whereas their corresponding sites in normal lung tissue were completely methylated (underlined). 


\section{MATERIALS AND METHODS}

\section{Patients and tissue specimens}

In this study, 179 lung squamous cell carcinoma (SCC) and adenocarcinoma samples were obtained randomly from patients who underwent surgery in the First Affiliated Hospital of China Medical University between 2007 and 2013. Among the 179 patients, 95 had complete follow-up records. The patient pool comprised of 92 men and 87 women, with a mean age of 60 years (range, 38-84 years). Histological diagnosis and grade of differentiation were determined by examination of hematoxylin-eosin stained sections in accordance with the classification system of the World Health Organization. Tumors were diagnosed as SCCs $(n=63)$ or adenocarcinomas $(n=116)$, and classified as well-differentiated $(n=52)$, moderately differentiated $(n=100)$ or poorly differentiated $(n=$ 27) tumors. Tumor stage was classified as stages I-III ( $n=87,72$ and 20, respectively) according to the TNM classification system of the International Union Against Cancer. Lymphatic metastasis was observed in 78 cases. Seventy fresh lung cancer samples and 30 of their corresponding normal lung tissues were also obtained from patients who underwent surgery at the First Affiliated Hospital of China Medical University in 2013 and stored at $-70^{\circ} \mathrm{C}$ immediately after resection. These samples were used for DNA extraction. The study was conducted under the regulations of the Institutional Review Board of China Medical University.

\section{Immunohistochemistry}

Specimens were fixed in 10\% neutral-buffered formalin for 24 hours, embedded in paraffin blocks and cut into 4- $\mu \mathrm{m}$ sections. These sections were deparaffinized, rehydrated, and then incubated with rabbit anti-TC1 antibody (1:200; Santa Cruz, CA), mouse anti-DNA methyltransferase-1 (DNMT1) antibody (1:200; Santa Cruz, CA), mouse anti- $\beta$-catenin antibody $(1: 200$; BD Transduction Laboratories, KY), rabbit anti-TCF4 antibody (1:200; Santa Cruz, CA), rabbit anti-Axin antibody (1:50; Santa Cruz, CA), rabbit anti-Disabled-2 (Dab2) antibody (1:200; Santa Cruz, CA) or rabbit anti-Chibby antibody (1:200; Santa Cruz, CA) at $4^{\circ} \mathrm{C}$ overnight. Detection of antibodies was performed using the streptavidin-peroxidase method. Some slides were stained in the absence of primary antibodies and served as negative controls.

\section{Evaluation of immunostaining}

Two investigators who were blind to the clinical data evaluated the immunostained sections. Five views per slide were examined, and 100 tumor cells were observed per view at $400 \times$ magnification. The positive rate of each case was obtained by calculating the percentage of positively stained cells in each slide. Percentage score of each case was assigned as follows: (1) $1-25 \%$, (2) $26-50 \%$, (3) $51-75 \%$, and (4) $76-100 \%$. The intensity of immunostaining was scored as $0,1,2$, or 3 if negative, weak, moderate, or marked, respectively. Scores from each tumor sample were multiplied to give a final score ranging $0-12$, and the tumors were categorized based on scores $\leq 6$ and $\geq 8$ as having low or high expression, respectively. When $\geq 10 \%$ of tumor cells per specimen were stained in the nuclear regions, the sample was scored as having positive nuclear expression.

\section{DNA extraction, PCR, and direct sequencing}

Genomic DNA was isolated from tissue samples with a tissue/cell DNA extraction reagent kit (Bioteke, Beijing, China) according to the manufacturer's protocol. The primers for C8orf4 gene were as follows: forward, 5'-CGATGAAAGCAAAGCGAAGCC -3', and reverse, 5'- GATAACGTCCTTATCCATCCTC -3'. PCR conditions included denaturation at $95^{\circ} \mathrm{C}$ for $5 \mathrm{~min}$, amplification for 30 cycles at $95^{\circ} \mathrm{C}$ for $20 \mathrm{~s}$, annealing at $55^{\circ} \mathrm{C}$ for $20 \mathrm{~s}$, and extension at $72^{\circ} \mathrm{C}$ for $40 \mathrm{~s}$, with a final step at $4^{\circ} \mathrm{C}$ for $5 \mathrm{~min}$. The PCR product of C8orf4 was $351 \mathrm{bp}$. PCR products were analyzed via electrophoresis on $1 \%$ agarose gels containing ethidium bromide, and observed using a Bio-Imaging system (UVP, Upland, CA). Purified PCR products were sequenced by Wanlei Life Sciences Co., Ltd., Shenyang, China.

\section{Bisulfite sequencing PCR (BSP) analysis}

Following DNA extraction, bisulfite conversion of DNA was performed using the EZ DNA Methylation kit (Zymo Research, Beijing, China) according to the manufacturer's instructions. The primers for BSP were as follows: forward, 5'-GGAGTTGAATTTCGGAAGAT-3'; reverse, 5'-ATTACCCACGACTTTCTTAC-3' (product length: $144 \mathrm{bp}$ ). The bisulfite-treated DNA was amplified for 30 cycles: $95^{\circ} \mathrm{C}$ for $5 \mathrm{~min}$, followed by cycling at $95^{\circ} \mathrm{C}$ for $10 \mathrm{~s}, 52^{\circ} \mathrm{C}$ for $20 \mathrm{~s}$, and $72^{\circ} \mathrm{C}$ for $30 \mathrm{~s}$, with a final step at $4^{\circ} \mathrm{C}$ for $5 \mathrm{~min}$. PCR products were analyzed using electrophoresis on $1.5 \%$ agarose gels containing ethidium bromide, and observed using a Bio-Imaging system (UVP, Upland, CA). Purified PCR products were sequenced by Wanlei Life Sciences Co., Ltd., Shenyang, China.

\section{Statistical analysis}

Pearson's chi-square and likelihood ratio tests were used to examine correlations between TC1 expression and clinicopathological factors. Spearman's correlation test was used to assay correlations between expression levels of these proteins. Non-parametric Wilcoxon signed ranks test was used to compare the difference between TC1 methylation status of lung cancers and the corresponding normal lung tissues. Kaplan-Meier method (log-rank test) 
and Multivariate Cox regression were used in follow-up analysis. Statistical significance was established at $P<0.05$.

\section{Abbreviations}

TC1: thyroid cancer 1; DNMT1: DNA methyltransferase-1; TCF/LEF: T-cell factor/lymphoid enhancer factor; Dab2: Disabled-2; SCC: squamous cell carcinoma; BSP: bisulfite sequencing PCR.

\section{Author contributions}

H.T.X. conceived and designed the research. H.T.X. and L.H.Y. draft the manuscript. Y.W.Z., L.Z., and Y.W. performed the experiments. S.Y.C., N.T., D.L.Y., and L.L. participated in the immunohistochemical staining, collected clinical data and performed follow-up analysis. L.L.B. and Q.C.L. evaluated immunostaining. X.P.Z. and G.Y.J. analyzed the data. X.S.Q. and E.H.W. revised the manuscript. All authors read and approved the final manuscript.

\section{ACKNOWLEDGMENTS}

This study was supported by the National Natural Science Foundation of China (Grant No. 81372497 to H.-T. Xu and Grant No. 81301930 to L.-H. Yang) and Program for Liaoning Excellent Talents in University (Grant No. LR2015067 to H.-T. Xu).

\section{CONFLICTS OF INTEREST}

The authors declare no conflicts of interest.

\section{REFERENCES}

1. Sunde M, McGrath KC, Young L, Matthews JM, Chua EL, Mackay JP, Death AK. TC-1 is a novel tumorigenic and natively disordered protein associated with thyroid cancer. Cancer Res. 2004; 64: 2766-2773.

2. Chua EL, Young L, Wu WM, Turtle JR, Dong Q. Cloning of TC-1 (C8orf4), a novel gene found to be overexpressed in thyroid cancer. Genomics. 2000; 69: 342-347.

3. Friedman JB, Brunschwig EB, Platzer P, Wilson $\mathrm{K}$, Markowitz SD. C8orf4 is a transforming growth factor $\mathrm{B}$ induced transcript downregulated in metastatic colon cancer. Int J Cancer. 2004; 111: 72-75.

4. Jung Y, Bang S, Choi K, Kim E, Kim Y, Kim J, Park J, Koo H, Moon RT, Song K, Lee I. TC1 (C8orf4) enhances the Wnt/beta-catenin pathway by relieving antagonistic activity of Chibby. Cancer Res. 2006; 66: 723-728.

5. Kim Y, Kim J, Park J, Bang S, Jung Y, Choe J, Song K, Lee I. TC1(C8orf4) is upregulated by IL-1beta/TNF-alpha and enhances proliferation of human follicular dendritic cells. FEBS Lett. 2006; 580: 3519-3524.
6. Takemaru K, Yamaguchi S, Lee YS, Zhang Y, Carthew RW, Moon RT. Chibby, a nuclear beta-catenin-associated antagonist of the Wnt/Wingless pathway. Nature. 2003; 422: 905-909.

7. Li FQ, Mofunanya A, Fischer V, Hall J, Takemaru K. Nuclear-cytoplasmic shuttling of Chibby controls betacatenin signaling. Mol Biol Cell. 2010; 21: 311-322.

8. Xu HT, Li QC, Dai SD, Xie XM, Liu DI, Wang EH. The expression patterns and correlations of chibby, beta-catenin, and DNA methyltransferase-1 and their clinicopathological significance in lung cancers. APMIS. 2011; 119: 750-758.

9. Krausova M, Korinek V. Wnt signaling in adult intestinal stem cells and cancer. Cell Signal. 2014; 26: 570-579.

10. Kim B, Koo H, Yang S, Bang S, Jung Y, Kim Y, Kim J, Park J, Moon RT, Song K, Lee I. TC1(C8orf4) correlates with Wnt/beta-catenin target genes and aggressive biological behavior in gastric cancer. Clin Cancer Res. 2006; 12: 3541-3548.

11. Gall $\mathrm{C}, \mathrm{Xu} \mathrm{H}$, Brickenden A, Ai X, Choy WY. The intrinsically disordered TC-1 interacts with Chibby via regions with high helical propensity. Protein Sci. 2007; 16: 2510-2518.

12. Kim J, Kim Y, Kim HT, Kim DW, Ha Y, Kim CH, Lee I, Song K. TC1(C8orf4) is a novel endothelial inflammatory regulator enhancing NF-kappaB activity. J Immunol. 2009; 183: 3996-4002.

13. Yang ZQ, Moffa AB, Haddad R, Streicher KL, Ethier SP. Transforming properties of TC-1 in human breast cancer: interaction with FGFR2 and beta-catenin signaling pathways. Int J Cancer. 2007; 121: 1265-1273.

14. Park J, Jung Y, Kim J, Kim KY, Ahn SG, Song K, Lee I. $\mathrm{TC} 1$ (C8orf4) is upregulated by cellular stress and mediates heat shock response. Biochem Biophys Res Commun. 2007; 360: 447-452.

15. Wang YD, Bian GH, Lv XY, Zheng R, Sun H, Zhang Z, Chen Y, Li QW, Xiao Y, Yang QT, Ai JZ, Wei YQ, Zhou Q. TC1 (C8orf4) is involved in ERK1/2 pathway-regulated G(1)- to S-phase transition. BMB Rep. 2008; 41: 733-738.

16. Jung Y, Kim M, Soh H, Lee S, Kim J, Park S, Song K, Lee I. TC1(C8orf4) regulates hematopoietic stem/progenitor cells and hematopoiesis. PLoS One. 2014; 9: e100311.

17. de Melo Martins PC, Parise Junior O, Pereira Hors C, Villela Miguel RE, da Costa Andrade VC, Garicochea B. C8orf4/TC-1 (thyroid cancer-1) gene expression in thyroid cancer and goiter. ORL J Otorhinolaryngol Relat Spec. 2007; 69: 127-130.

18. Xu HT, Liu Y, Liu SL, Miao Y, Li QC, Wang EH. TC-1 (C8orf4) expression is correlated with differentiation in ovarian carcinomas and might distinguish metastatic ovarian from metastatic colorectal carcinomas. Virchows Arch. 2013; 462: 281-287.

19. Zhang P, Cao HY, Bai LL, Li WN, Wang Y, Chen SY, Zhang L, Yang LH, Xu HT, Wang EH. The high expression of TC1 (C8orf4) was correlated with the expression of 
beta-catenin and cyclin D1 and the progression of squamous cell carcinomas of the tongue. Tumour Biol. 2015; 36: 7061-7067.

20. Zhang J, Gao Y, Zhao X, Guan M, Zhang W, Wan J, Yu B. Investigation of copy-number variations of C8orf4 in hematological malignancies. Med Oncol. 2011; 28: S647-652.

21. Walter MJ, Payton JE, Ries RE, Shannon WD, Deshmukh H, Zhao Y, Baty J, Heath S, Westervelt P, Watson MA, Tomasson MH, Nagarajan R, O'Gara BP, et al. Acquired copy number alterations in adult acute myeloid leukemia genomes. Proc Natl Acad Sci U S A. 2009; 106: 12950-12955.

22. Zhu P, Wang Y, Du Y, He L, Huang G, Zhang G, Yan X, Fan Z. C8orf4 negatively regulates self-renewal of liver cancer stem cells via suppression of NOTCH2 signalling. Nat Commun. 2015; 6: 7122.

23. Su K, Huang L, Li W, Yan X, Li X, Zhang Z, Jin F, Lei J, Ba G, Liu B, Wang X, Wang Y. TC-1 (c8orf4) enhances aggressive biologic behavior in lung cancer through the Wnt/beta-catenin pathway. J Surg Res. 2013; 185: 255-263.

24. Lei J, Li W, Yang Y, Lu Q, Zhang N, Bai G, Zhong D, Su K, Liu B, Li X, Wang Y, Wang X. TC-1 overexpression promotes cell proliferation in human non-small cell lung cancer that can be inhibited by PD173074. PLoS One. 2014; 9: e100075.

25. Xu HT, Yang LH, Li QC, Liu SL, Liu D, Xie XM, Wang EH. Disabled-2 and Axin are concurrently colocalized and underexpressed in lung cancers. Hum Pathol. 2011; 42: 1491-1498.

26. Xie XM, Zhang ZY, Yang LH, Yang DL, Tang N, Zhao HY, Xu HT, Li QC, Wang EH. Aberrant hypermethylation and reduced expression of disabled-2 promote the development of lung cancers. Int J Oncol. 2013; 43: 1636-1642.

27. Schmitz Y, Rateitschak K, Wolkenhauer O. Analysing the impact of nucleo-cytoplasmic shuttling of beta-catenin and its antagonists APC, Axin and GSK3 on Wnt/beta-catenin signalling. Cell Signal. 2013; 25: 2210-2221.

28. Song J, Du Z, Ravasz M, Dong B, Wang Z, Ewing RM. A protein interaction between beta-Catenin and Dnmt1 regulates Wnt signaling and DNA methylation in colorectal cancer cells. Mol Cancer Res. 2015; 13: 969-981.

29. Jang H, Kim M, Lee S, Kim J, Woo DC, Kim KW, Song K, Lee I. Adipose tissue hyperplasia with enhanced adipocytederived stem cell activity in Tc1(C8orf4)-deleted mice. Sci Rep. 2016; 6: 35884. 